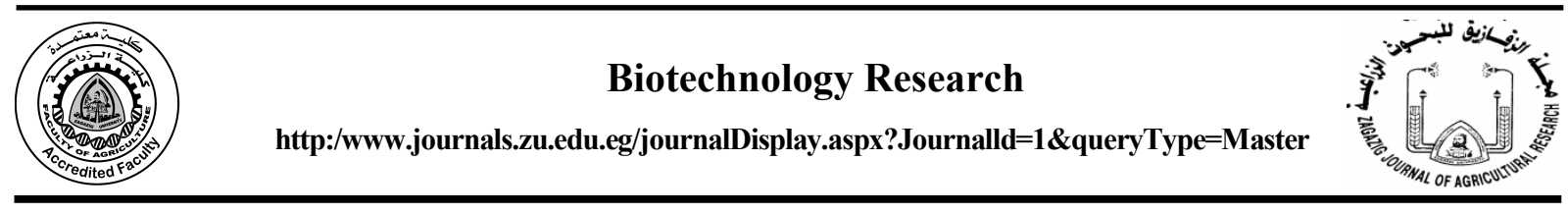

\title{
ISOLATION AND CHARACTERIZATION OF QUERCETIN AND KAEMPFEROL FROM Ginkgo biloba LEAVES GROWN IN EGYPT
}

\author{
Ahmed A. Ali", A. Osman, A.M. Abo Eita and M.Z. Sitohy \\ Agric. Biochem. Dept., Fac. Agric., Zagazig Univ., Egypt
}

Received: 08/07/2019 ; Accepted: 28/07/2019

\begin{abstract}
In the present study, Ginkgo biloba leaves were extracted with methanol $80 \%$ and fractionated by sequential extraction with petroleum ether (Fr-l), ethyl ether (Fr-II) and ethyl acetate (Fr-III) separately. Fraction III was co-chromatographed after hydrolyzed with $7 \%$ sulphuric acid with 3 solvent systems. Paper chromatography on Whatman cellulose chromatography papers 3 CHR with benzene, acetic acid and water (125: 72: 3) as mobile phase enabled good separation of quercetin at $0.6 \mathrm{R}_{\mathrm{F}}$ and kaempferol at $0.78 \mathrm{R}_{\mathrm{F}}$. In the present study, quercetin and kaempferol were isolated from Ginkgo biloba leaves grown in Egypt and characterized by various spectral studies. The ethanolic extract of Ginkgo biloba leaves was subjected to high-performance liquid chromatography analysis for the identification of major phenolics and flavonoids. Eleven components were detected. Most flavonoids in Ginkgo biloba leaves are the derivatives of quercetin, and kaempferol. The results were obtained from UV and FTIR indicated for the molecular structure of quercetin and kaempferol. The mass spectrum of kaempferol and quercetin was observed at $\mathrm{m} / \mathrm{z} 286.8$ and 302.9 , respectively. The results of the present study established the presence of biologically active phytochemicals in the Ginkgo biloba leaves. The results also suggested that the Ginkgo biloba leaves extract contain significant amounts of quercetin and kaempferol. Thus, it may be concluded that the Ginkgo biloba leaves have great potential for producing healthy and highly nutritive products.
\end{abstract}

Key words: Ginkgo biloba leaves, quercetin, kaempferol, FTIR, mass analysis

\section{INTRODUCTION}

Ginkgo biloba L. (common name-maiden hair tree; family Ginkgoaceace) is traditionally as well as an economically important plant. The medicinal parts of Ginkgo (fresh or dried leaves, and seeds separated from their fleshy outer layer) are known for antioxidant, anti-asthmatic, wound healing, neuroprotective and antimicrobial properties and to improve the mental capacity in Alzheimer's patients (Mazzanti et al., 2000; Sati et al., 2012; Xu et al., 2012). The medicinal and the antimicrobial properties of Ginkgo can be attributed to two important chemical constituents, viz. terpenes trilactone (ginkgolides and bilobalide) and flavonoid glycosides (Craig, 1999; Van Beek and Montoro, 2009). Flavonoids, abundant in vegetables, fruits, medicinal plants, teas have attracted the greatest attention and have been studied extensively because they are a kind of highly effective antioxidants with lower toxicity than synthetic antioxidants such as butylated hydroxyl touline (BHT) and butylated hydroxy anisole (BHA) (Pekkarinen et al., 1999). Ginkgo biloba leaf has a long history of medicinal use for the treatment of numerous conditions, going back thousands of years. Extracts of Ginkgo biloba leaves contain a wide variety of active compounds and are a particularly rich source of flavonoids, primarily quercetin, kaempferol, and isorhamnetin. Ginkgo has become an increasingly well-known medicinal plant worldwide and is now among the best-selling phytomedicines in Europe, where it is prescribed as a treatment for peripheral vascular disorders,

\footnotetext{
*Corresponding author: Tel. : +201285391439

E-mail address: el.da3osy@gmail.com
} 
particularly cerebral insufficiency, including general dementia and Alzheimer's disease (Itil and Martorano, 1995). The most important substances are flavonoids (ginkgo flavone glycosides) and terpenoids (ginkgolides and bilobalide) (Craig, 1999). The various compounds found in ginkgo may play a protective role in different stages of the decline of intellectual function via several mechanisms of action: vasoregulating activity of arteries, capillaries, and veins (increased blood flow); platelet activating factor (PAF) antagonism; homeostasis of inflammation and oxidative stress; prevention of cell membrane damage caused by free radicals and neurotransmission modulation (Itil and Martorano, 1995). Therefore, in the present study quercetin and kaempferol were isolated from Ginkgo biloba leaves and characterized by various spectral studies.

\section{MATERIALS AND METHODS}

\section{Collection of Plant Materials}

Leaves of Ginkgo biloba L were collected from Orman Park, Giza, Egypt. Ginkgo biloba L leaves were manually cleaned and ground for 3 min using a Moulinex mixer (Type 716, France) at the maximum speed setting. Ground leaves were passed through a $1 \mathrm{~mm}^{2}$ sieve.

\section{Extraction Procedure}

Sample of twenty grams was extracted individually with $200 \mathrm{ml}$ ethanol 99.7 using soxhlet apparatus for $6 \mathrm{hr}$., at $60^{\circ} \mathrm{C}$ followed by filtration through Whatman No. 42 filter paper. The soxhlet was hydrolyzed by the reflux with 3 $\mathrm{ml}$ of conc. $\mathrm{HCl}$ and $5 \mathrm{ml}$ of $\mathrm{H}_{2} \mathrm{O}$ for $2.5 \mathrm{hr}$., (Kaur et al., 2012) to detect the flavonoid glycosides in the HPLC. The final hydrolyzed filtrate was thereof filtered using Whatman filter paper (No. 42). The filtrate was concentrated using a rotary evaporator to obtain the constant mass of respective extract. Concentrated extracts were dissolved in Methanol and sonicated for 15 $\min$ at $40^{\circ} \mathrm{C}$. The prepared samples were filtered through a $0.45 \mathrm{~mm}$ filter prior to HPLC analysis and kept in airtight at $4{ }^{\circ} \mathrm{C}$ until further analysis.

\section{HPLC Analysis}

HPLC analysis was carried out according to Sati et al. (2019) with slight modifications using an Agilent Technologies 1100 series liquid chromatograph equipped with an auto-sampler and a diode-array detector. The analytical column was Agilent Eclipse XDB C18 (150 x $4.6 \mu \mathrm{m} ; 5 \mu \mathrm{m})$ with a $\mathrm{C} 18$ guard column. The mobile phase consisted of acetonitrile (solvent A) and $2 \%$ acetic acid in water $(V / V)$ (solvent B). The flow rate was kept at $0.8 \mathrm{~mL} \mathrm{~min}^{-1}$ for a total run time of $70 \mathrm{~min}$ and the gradient program was as follows: $100 \% \mathrm{~B}$ to $85 \% \mathrm{~B}$ in $30 \mathrm{~min}, 85 \% \mathrm{~B}$ to $50 \% \mathrm{~B}$ in $20 \mathrm{~min}, 50 \% \mathrm{~B}$ to $0 \% \mathrm{~B}$ in $5 \mathrm{~min}$ and $0 \% \mathrm{~B}$ to $100 \% \mathrm{~B}$ in $5 \mathrm{~min}$. There was $10 \mathrm{~min}$ of post-run for reconditioning. The injection volume was $10 \mu 1$ and peaks were monitored simultaneously at 280, 320 and 360 $\mathrm{nm}$ for the benzoic acid, cinnamic acid derivatives and flavonoids compound, respectively. All samples were filtered through a $0.45 \mu \mathrm{m}$ Acrodisc syringe filter (Gelman Laboratory, MI) before injection. Peaks were identified by congruent retention times and UV spectrum and compared with those of the standards.

\section{Quercetin and Kaempferol Isolation and Purification}

\section{Chromatography}

Paper chromatography (PC): Whatman cellulose chromatography papers $(3 \mathrm{CHR}, \mathrm{W} \times$ L $460 \mathrm{~mm} \times 570 \mathrm{~mm}$, pkg of 100 each, WHA3003917 Aldrich). Solvent systems: system 1 (S-1): n-butanol, acetic acid, water (4:1:5 (V/V), upper layer), system 2 (S-2): nbutanol, acetic acid, water $(3: 1: 1)(V / V)$ and system 3 (S-3): benzene, acetic acid and water (125: 72: 3) $(V / V)$.

Column chromatography: Polyamide column (S-7). Fractions were eluted with $40 \%$ aqueous methanol.

\section{Isolation and purification}

Ginkgo biloba leaves powder $(50 \mathrm{~g})$ were Soxhlet's extracted with $80 \%$ methanol for 24 $\mathrm{hr}$. The methanol soluble fractions were filtered, concentrated in vacuum and the aqueous 
fractions were fractioned by sequential extraction with petroleum ether (Fr- 1), ethyl ether (Fr-II) and ethyl acetate (Fr-III) separately. Each step was repeated thrice for complete extraction, fraction I was discarded because it contained fatty substances, whereas fraction II and III were concentrated and used for flavonoids separation.

Fraction III was further hydrolyzed by refluxing with $7 \%$ sulphuric acid $(10 \mathrm{ml} / \mathrm{g}$ plant material for $2 \mathrm{hr}$.), filtered and the filtrate was extracted thrice with ethyl acetate. All ethyl acetate layers were pooled together separately, neutralized by distilled water with repeated washings, and concentrated in vacuum. Both fraction II and fraction III were taken up in small volume of ethanol $(2-5 \mathrm{ml})$ before chromatographic examination.

Each of the extract was co-chromatographed with authentic samples of flavonoids (Kaempferol and quercetin) as markers. Papers were developed in an air- tight chromatographic chamber saturated with solvent mixture .The developed sheets were air dried and visualized under UV light and by exposure to ammonia fumes. The mouth of a $100 \mathrm{ml}$ bottle containing concentrated $\mathrm{NH}_{4} \mathrm{OH}$ was held in contact with each spot for about 5-10 seconds and fluorescent spots corresponding to that of standard markers were marked. The colored spots thus developed were noted and the $R_{F}$. value of each spot was calculated. Several other solvent systems such as n-butanol, acetic acid, water (4:1:5(V/V), upper layer), n-butanol, acetic acid, water (3:1:1) $(V / V)$ were also tested, but the solvent system containing benzene, acetic acid and water (125: 72: 3) $(V / V)$ gave better results.

Kaempferol and quercetin have been obtained from Fr-III (ethyl acetate fraction) according to the observation on paper chromatography as compared to authentic samples. Then, Kaempferol and quercetin was eluted from paper chromatograms by dispersion in $40 \%$ aqueous methanol $\left(40 \% \mathrm{H}_{2} \mathrm{O}-\mathrm{MeOH}\right)$ and was filtered using Whatman filter paper (No. 42). The filtrate was purified on a polyamide column (S-7).

\section{Kaempferol and quercetin identification}

\section{$\mathbf{R}_{\mathrm{f}}$ value}

The $R_{\mathrm{f}}$ value is defined as the ratio of the distance moved by the solute and the distance moved by the solvent along with the paper.

$$
\mathrm{Rf}=\frac{\text { Distance moved by the solute }}{\text { Distance moved by the solvent }}
$$

\section{Fourier transform infrared (FTIR) spectroscopy}

Kaempferol and quercetin were prepared with potassium bromide $(\mathrm{KBr})$ pellet method (Souillac et al., 2002). Infrared spectra were measured with a FT-IR spectrometer (NICOLET NEXUS 470, DTGS, Thermo Scientific, Waltham, MS, USA) at $25^{\circ} \mathrm{C}$. For each spectrum 256 interferograms were collected with a resolution of $4 \mathrm{~cm}^{-1}$ with 64 scans and a $2 \mathrm{~cm}^{-1}$ interval from the 4000 to $400 \mathrm{~cm}^{-1}$ region. The system was continuously purged with dry air. Second derivation spectra were obtained with SavitskyGolay derivative function soft (Surewicz and Mantsch, 1988).

\section{UV spectroscopy (selection of $\lambda_{\max }$ )}

Kaempferol and quercetin were diluted with methanol to get $(10 \mu \mathrm{g} / \mathrm{ml})$ concentration. This solution was scanned between the wavelength regions of 200-400 $\mathrm{nm}$ against methanol as blank. The maximal absorption was recorded as $\lambda_{\max }$ (Telange et al., 2014).

\section{Mass analysis}

An advion compact mass spectrometer (CMS) NY/USA instrument equipped with an electro spray ionization source (ESI) was employed to analyze the composition of isolated compounds (diluted with methanol to get $10 \mu \mathrm{g} / \mathrm{ml}$ concentration) with the following specification:

Ion source: ESI; Polarity: Positive and negative ion switching in a single analysis; Flow rate range: $10 \mu \mathrm{l} / \mathrm{min}$ to $2 \mathrm{ml} / \mathrm{min} ; \mathrm{m} / \mathrm{z}$ range: expression $\mathrm{S} \mathrm{m} / \mathrm{z} 10$ to 1.200 and expression $\mathrm{L}$ $\mathrm{m} / \mathrm{z} 10$ to 2.000 ; Acquisition speed: $10.000 \mathrm{~m} / \mathrm{z}$ units/sec., Sensitivity: $10 \mathrm{pg}$ reserpine; Accuracy: \pm $0.1 \mathrm{~m} / \mathrm{z}$ units of the entire acquisition range; Stability: $0.1 \mathrm{~m} / \mathrm{z}$ units at m/z 1.200 over $12 \mathrm{hr}$. 
period operating temperature of $20^{\circ} \mathrm{C} \pm 1{ }^{\circ} \mathrm{C}$; Polarity switching speed: $50 \mathrm{~ms}$; dynamic range: 4.5 orders of magnitude.

\section{RESULTS AND DISCUSSION}

\section{HPLC Analysis}

The bioactive phenolic compounds identified in the Ginkgo biloba leaves are listed in Table 1 and Fig. 1. 17 components were represented. Gentisic acid, chlorogenic acid, caffeic acid, vanillic acid, sinapic acid, and rutin were dose not detected. 11 components were detected (gallic acid, protochatchuic acid, catachine, syrngic acid, ferulic acid, coumarin, rosmarinic acid, cinnamic acid, quercetin, kaempferol and chyrsin). The main components were catachine, chyrsin, rosmarinic acid, protochatchuic acid and coumarin (64.632, 43.546, 41.301, 20.191 and $12.512 \mu \mathrm{g} / \mathrm{ml}$, respectively). Most flavonoids in Ginkgo biloba leaves are the derivatives of isorhamnetin, quercetin, and kaempferol (Ding et al., 2009). In the present study quercetin, and kaempferol was recorded 9.964 and 6.157 $\mu \mathrm{g} / \mathrm{ml}$, respectively at retention time 43.4 and $46.4 \mathrm{~min}$, respectively. These results are in agreement with those obtained by Ding $\boldsymbol{e t} \boldsymbol{a l}$. (2009) and Sati et al. (2019).

\section{Quercetin and Kaempferol Identification}

$$
R_{F} \text { value }
$$

Paper chromatography on Whatman cellulose chromatography papers 3 CHR with benzene, acetic acid and water (125: 72: 3) $(V / V)$ as mobile phase enabled good separation of quercetin at $0.6 \mathrm{R}_{\mathrm{F}}$ and kaempferol at $0.78 \mathrm{R}_{\mathrm{F}}$.

\section{FT-IR spectroscopy}

The IR spectrum of the quercetin is shown in Fig. 2A. The absorption around $3417 / \mathrm{cm}$ is due to the presence of phenolic hydroxyl groups in the compound. The intense absorption band at $1644 / \mathrm{cm}$ is due to the presence of $v(\mathrm{C}=\mathrm{O})$. The band around $1458 / \mathrm{cm}$ is due to the occurrence of the aromatic group in an isolated compound. The IR spectrum of the kaempferol is shown in
Figure 2B. The FT-IR spectrum revealed broad absorption bands at $3391 / \mathrm{cm}$ represents to $\mathrm{OH}$ group stretching. The absorption band occurs at $1664 / \mathrm{cm}$ for the carbonyl group $(\mathrm{C}=\mathrm{O})$ and the absorption band at $1567,1449 / \mathrm{cm}$ denotes the presence of aromatic ring. Moreover, the band around $2900 / \mathrm{cm}$ corresponds to the presence of $\mathrm{C}-\mathrm{H}$ stretching. This result is in good agreement with the previous literature for molecular structure of quercetin and kaempferol (Chourasiya et al., 2012; Sathyadevi and Subramanian, 2015; Sambandam et al., 2016).

\section{UV-spectrum}

The absorption maximum $\left(\lambda_{\max }\right)$ was found to be $258 \mathrm{~nm}$ and $375 \mathrm{~nm}$ for quercetin and $265 \mathrm{~nm}$ and $365 \mathrm{~nm}$ for kaempferol. This result is closely to those obtained by Chaudhari et al. (2014) and Telange et al. (2014).

\section{Mass analysis}

An advion compact mass spectrometer (CMS) NY/USA instrument equipped with an electro spray ionization source (ESI) was employed to analyze the composition of isolated quercetin and kaempferol. The mass spectrum of quercetin is illustrated in Fig. 3. 100\% base peak for compound, was observed at $\mathrm{m} / \mathrm{z} 302.9$ in the mass spectrum indicating the compound as quercetin. The mass spectrum of kaempferol is illustrated in Fig. 4. $100 \%$ base peak for compound, was observed at $\mathrm{m} / \mathrm{z} 286.8$ in the mass spectrum indicating the compound as kaempferol. This result is closely to those obtained by Chaudhari et al. (2014) and Telange et al. (2014).

\section{Conclusions}

The results of the present study established the presence of biologically active phytochemicals in the Ginkgo biloba leaves. The data also suggested that the Ginkgo biloba leaves extract to contain significant amounts of quercetin and kaempferol. Thus, it may be concluded that the Ginkgo biloba leaves have great potential for producing healthy and highly nutritive products. 
Zagazig J. Agric. Res., Vol. 46 No. (5) 2019

Table 1. Bioactive phenolic compounds $(\mu \mathrm{g} / \mathrm{ml})$ in Ginkgo biloba leaves

\begin{tabular}{lcc}
\hline Compound & Retention time (min) & Conc. (ug/ml) \\
\hline Gallic acid & 5.6 & 2.314 \\
Protochatchuic acid & 9.7 & 20.191 \\
Gentisic acid & 16.7 & $\mathrm{ND}$ \\
Catachine & 18.4 & 64.632 \\
Chlorogenic acid & 20.3 & $\mathrm{ND}$ \\
Caffeic acid & 21 & $\mathrm{ND}$ \\
Syrngic acid & 22.5 & 4.587 \\
Vanillic acid & 24.1 & $\mathrm{ND}$ \\
Ferulic acid & 32 & 4.610 \\
Sinapic acid & 33.5 & $\mathrm{ND}$ \\
Rutin & 36.1 & $\mathrm{ND}$ \\
Coumarin & 36.7 & 12.512 \\
Rosmarinic acid & 40.1 & 41.301 \\
Cinnamic acid & 42.7 & 0.909 \\
Quercetin & 43.4 & 9.694 \\
Kaempferol & 46.4 & 6.157 \\
Chyrsin & 51.7 & 43.546 \\
\hline
\end{tabular}

(A): Standard compounds

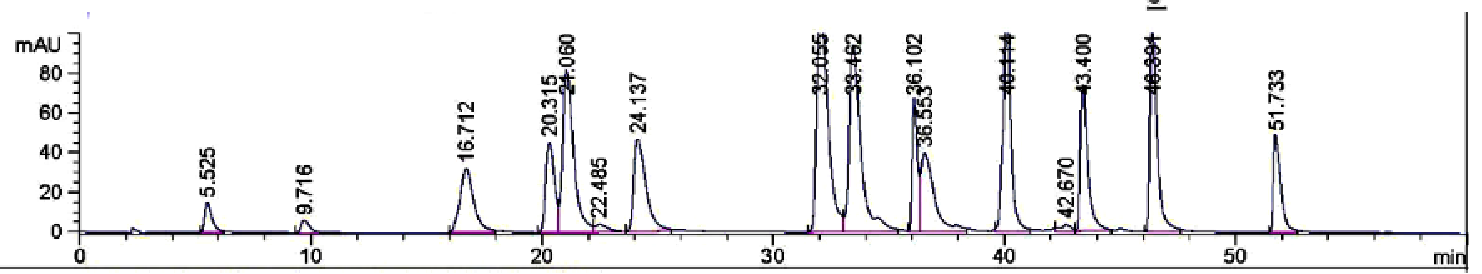

(B): Sample

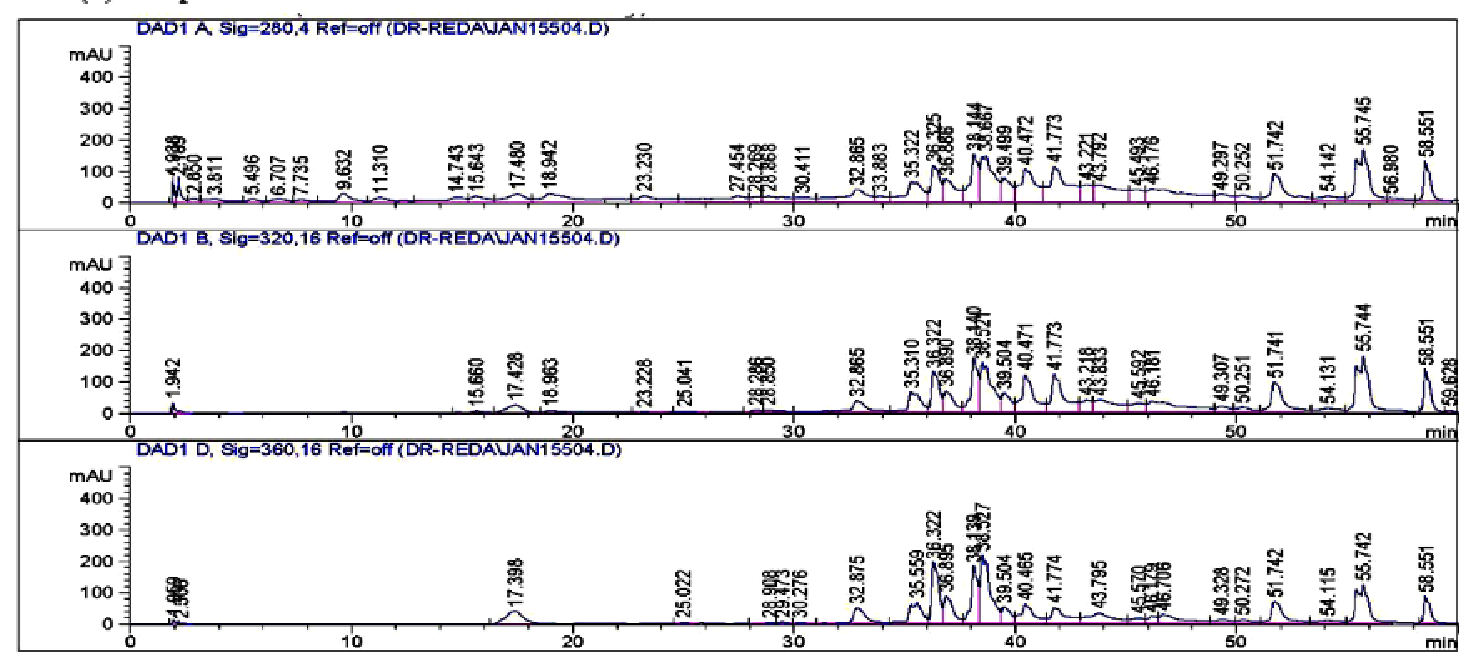

Fig. 1. Representative chromatogram of Ginkgo biloba leaves flavonoid glycosides. A: standard compounds and B: sample measured at 280,320 and $360 \mathrm{~nm}$ for the benzoic acid, cinnamic acid derivatives and flavonoid compounds, respectively 
(A): Quercetin

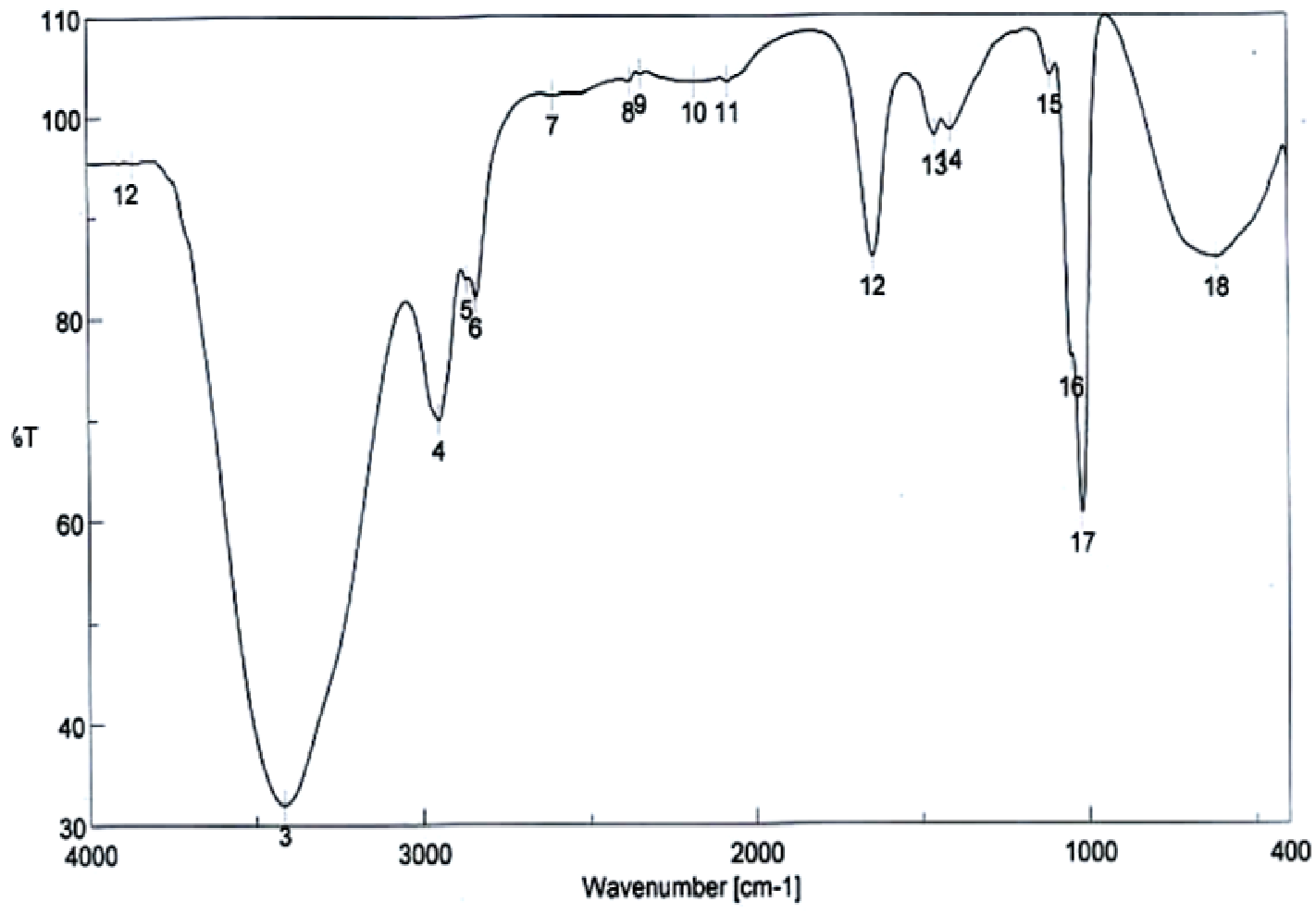

(B): kaempferol

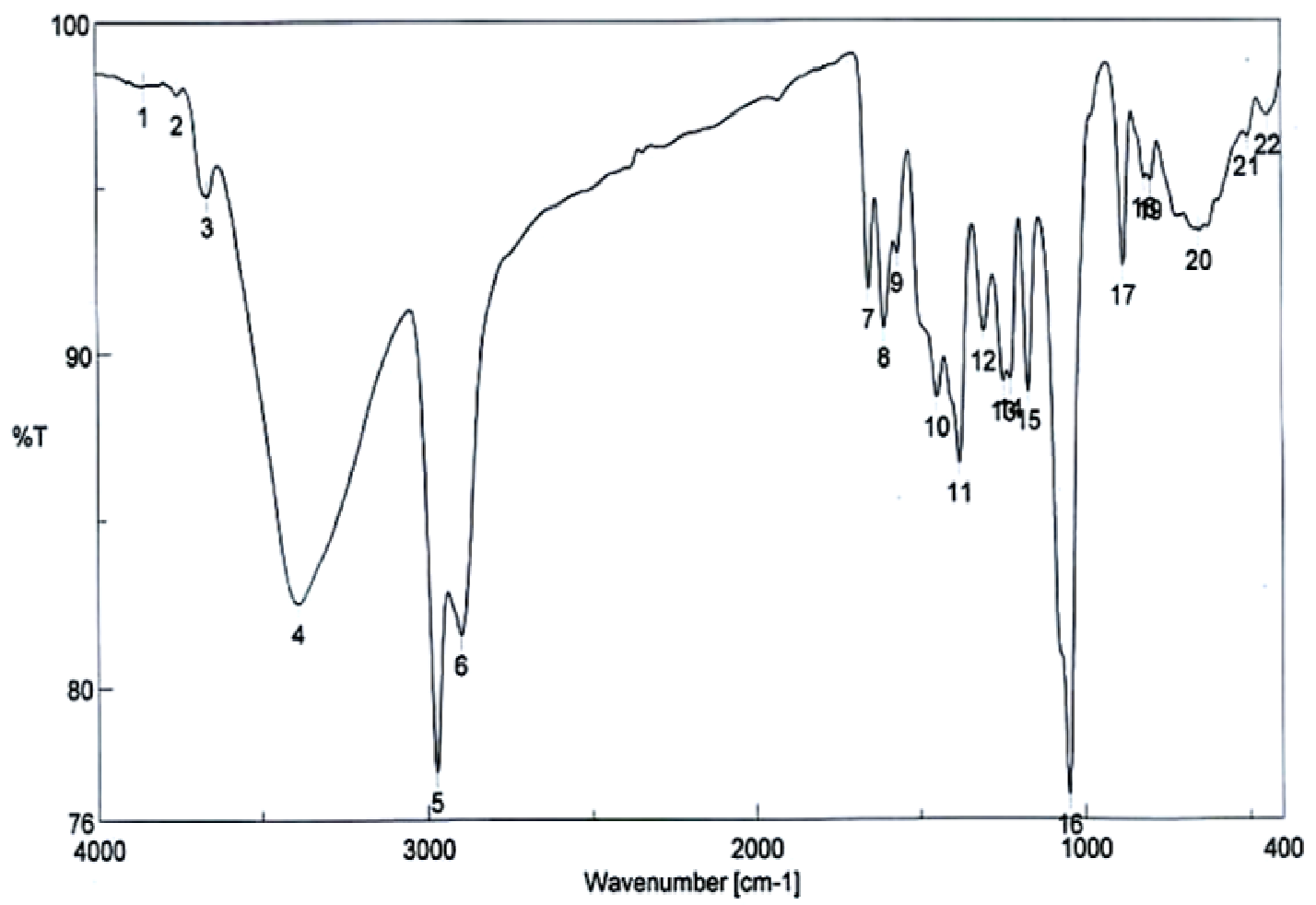

Fig. 2. FT-IR spectrum of isolated compounds (quercetin A and kaempferol B) 


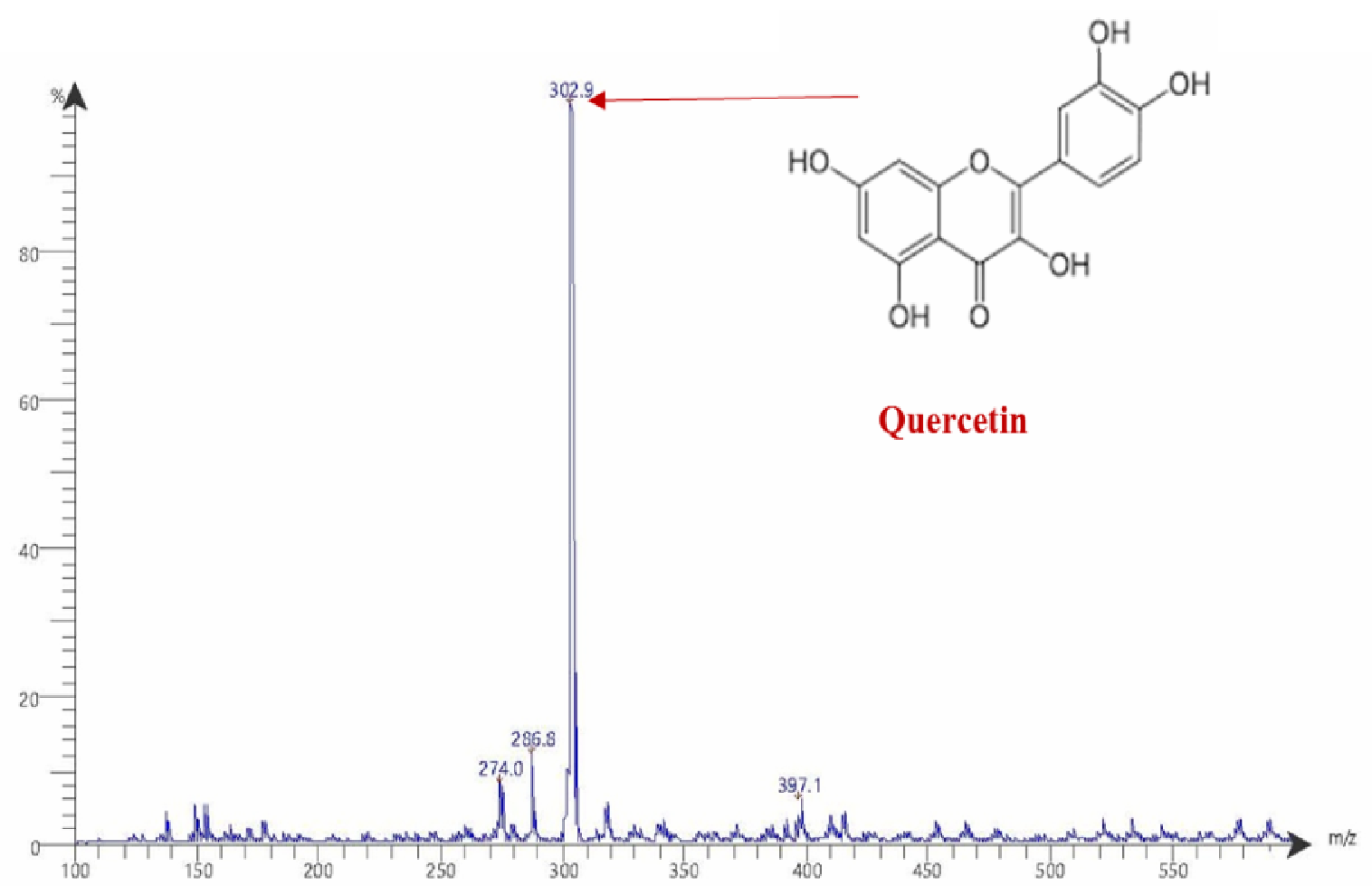

Fig. 3. Mass spectrum of quercetin stated by Chaudhari et al. (2014) and Telange et al. (2014)

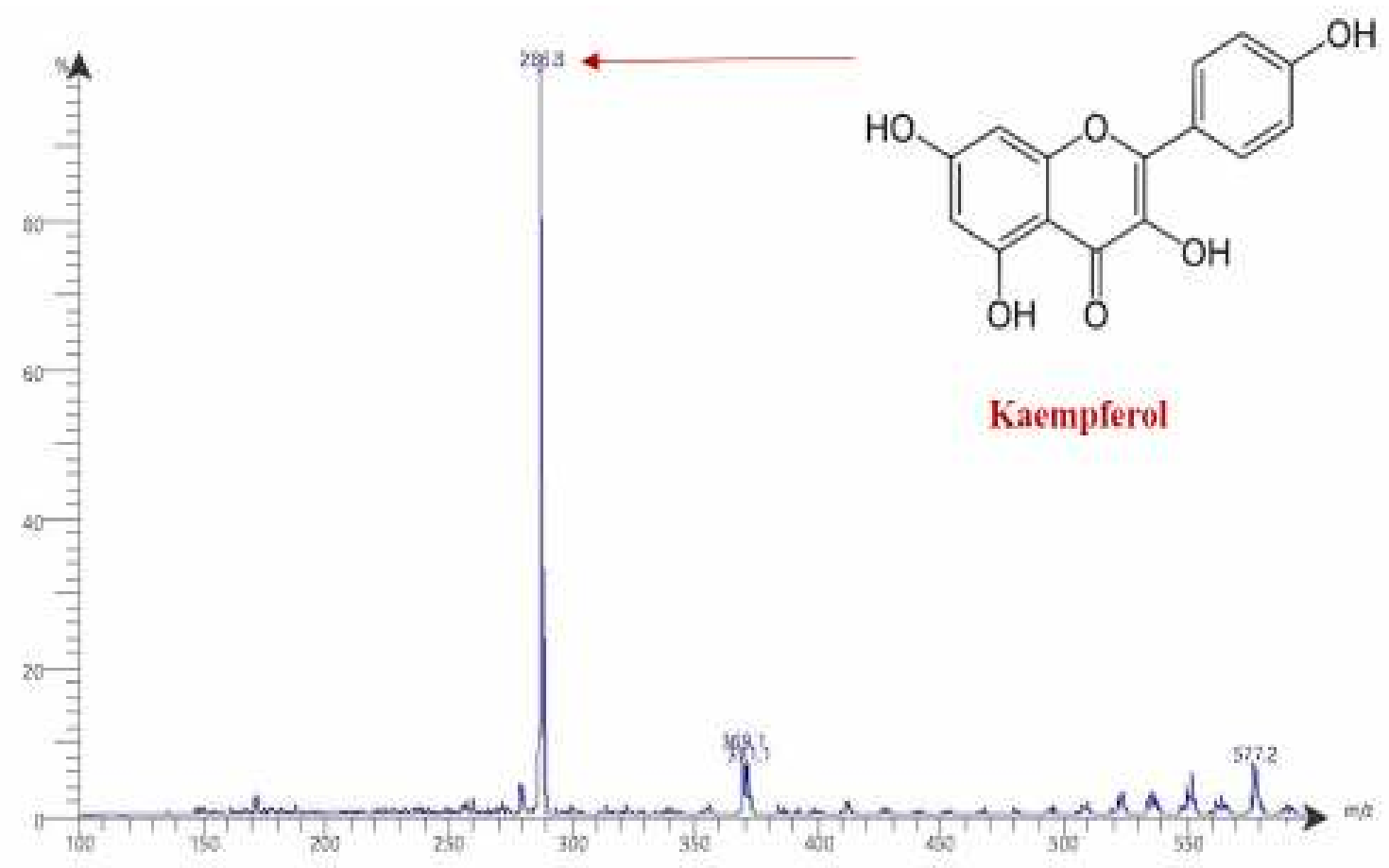

Fig. 4. Mass spectrum of kaempferol stated by Chaudhari et al. (2014) and Telange et al. (2014) 


\section{REFERENCES}

Chaudhari, S., J. Bangar, G. Akuskar and M. Ratnaparkhi (2014). Development and validation of UV spectrophotometric method for simultaneous estimation of rutin and quercetin in niosome formulation. Der Pharmacia Lettre 6, 271-276.

Chourasiya, A., A. Upadhaya and R. Shukla (2012). Isolation of quercetin-from leaves of Azadirachta indica and anti-diabetic study of the crude extracts. J. Pharm. and Biomed. Sci., 25: 179-181.

Craig, W.J. (1999). Health-promoting properties of common herbs. Ame. J. Clinical Nutr., 70: 491s-499s.

Ding, X.P., J. Qi, Y.X. Chang, L.L. Mu, D.N. Zhu and B.Y. Yu (2009). Quality control of flavonoids in Ginkgo biloba leaves by highperformance liquid chromatography with diode array detection and on-line radical scavenging activity detection. J. Chromatography A 1216, 2204-2210.

Itil, T. and D. Martorano (1995). Natural substances in psychiatry (Ginkgo biloba in dementia). Psychopharmacology Bulletin.

Kaur, P., A. Chaudhary, R.D. Singh, R. Prasad and B. Singh (2012). Spatial and temporal variation of secondary metabolite profiles in Ginkgo biloba leaves. Chem. and Biodiv., 9: 409-417.

Mazzanti, G., M. Mascellino, L. Battinelli, D. Coluccia, M. Manganaro and L. Saso (2000). Antimicrobial investigation of semipurified fractions of Ginkgo biloba leaves. J. Ethnopharmacol., 71: 83-88.

Pekkarinen, S.S., I.M. Heinonen and A.I. Hopia (1999). Flavonoids quercetin, myricetin, kaemferol and $(+)$-catechin as antioxidants in methyl linoleate. J. Sci. Food and Agric., 79: 499-506.

Sambandam, B., D. Thiyagarajan, A. Ayyaswamy, P. Raman, J. Kulasekaran and H. Venkatasamy (2016). Extraction and isolation of flavonoid quercetin from the leaves of Trigonella foenum-graecum and their anti-oxidant activity. Int. J. Pharm. Pharm. Sci., 8: 120-124.

Sathyadevi, M. and S. Subramanian (2015). Extraction, isolation and characterization of bioactive flavonoids from the fruits of Physalis peruviana Linn extract. Asian J. Pharm. and Clin. Res., 8.

Sati, P., A. Pandey and L.M.S. Palni (2012). Antimicrobial potential of leaf extracts of Ginkgo biloba L., growing in Uttarakhand, India. Nat. Acad. Sci. Letters, 35: 201-206.

Sati, P., P. Dhyani, I.D. Bhatt and A. Pandey (2019). Ginkgo biloba flavonoid glycosides in antimicrobial perspective with reference to extraction method. J. Trad. and Comp. Med., 9: 15-23.

Souillac, P.O., C.R. Middaugh and J.H. Rytting (2002). Investigation of protein/carbohydrate interactions in the dried state. 2. Diffuse reflectance FTIR studies. Int. J. Pharm., 235: 207-218.

Surewicz, W.K. and H.H. Mantsch (1988). New insight into protein secondary structure from resolution-enhanced infrared spectra. Biochimica et Biophysica Acta (BBA)Protein Structure and Molecular Enzymol., 952: 115-130.

Telange, D.R., A.T. Patil, A. Tatode and B. Bhoyar (2014). Development and Validation of UV Spectrophotometric Method for the Estimation of Kaempferol in Kaempferol: Hydrogenated Soy PhosphatidylCholine (HSPC) Complex. Pharm. Methods, 5.

Van Beek, T.A. and P. Montoro (2009). Chemical analysis and quality control of Ginkgo biloba leaves, extracts, and phytopharmaceuticals. J. Chrom. A, 1216: 2002-2032.

Xu, S.L., R.C. Choi, K.Y. Zhu, K.W. Leung, A.J. Guo, D. Bi, H. Xu, D.T. Lau, T.T. Dong and K.W. Tsim (2012). Isorhamnetin, a flavonol aglycone from Ginkgo biloba L., induces neuronal differentiation of cultured PC12 cells: potentiating the effect of nerve growth factor. Evidence-Based Comp. and Alter. Med. 
عزل وتوصيف الكيرسيتين والكمبيفيرول من أوراق الجنكه بيلوبا المزروعة في مصر

$$
\text { أحمد على علي - على عثمان محمد _ أحمد محمد أبوعيطه - محمود زكي سطوحى الكيمياء الحيوية الزر اعية - كلية الزر اعة - جامعة الزقازيق - الزقازيق - مصر }
$$

تم الكثف عن ال 1 مركب فينولى، معظم مركبات الفلافونويد الموجودة في أوراق الجنكة بيلوبا هي مشتقات الكيرسيتين

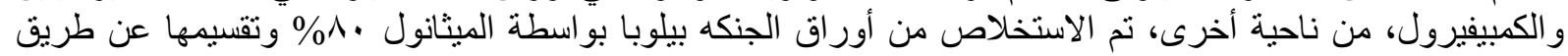

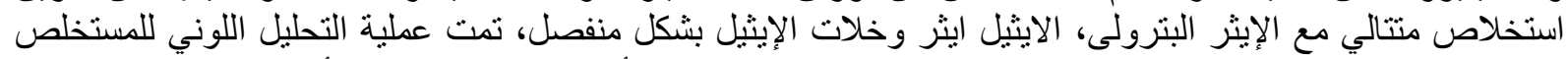

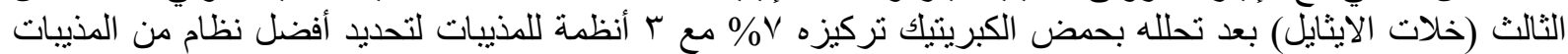

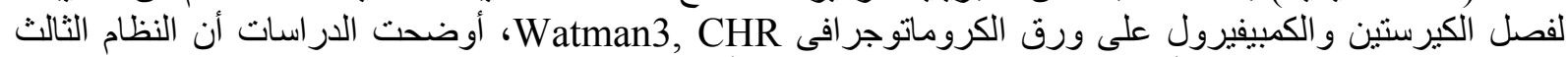

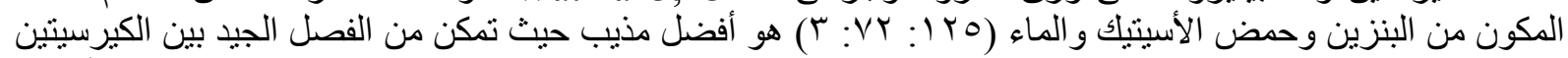

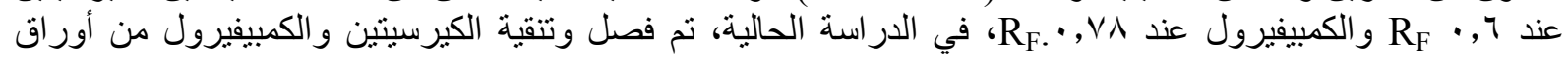

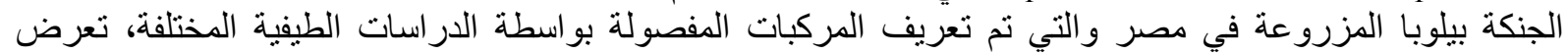

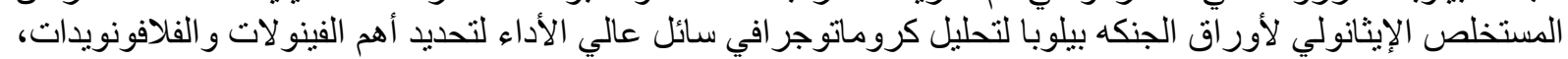

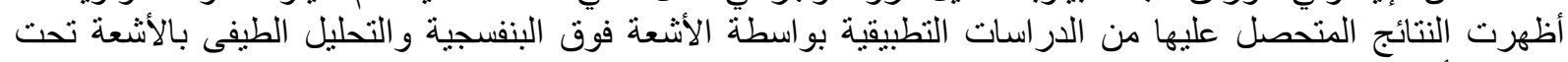

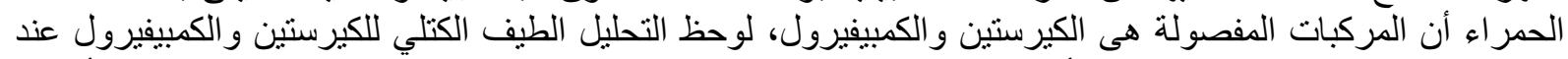

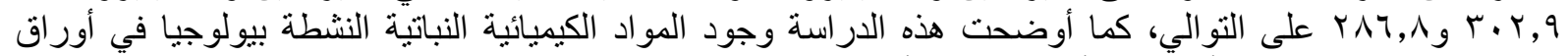

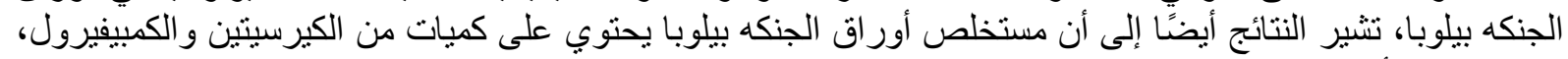

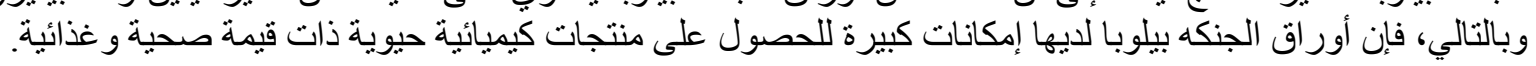

